\title{
The importance of sub-mesoscale processes for the exchange of properties through the Strait of Gibraltar
}

\author{
M. Bruno ${ }^{\mathrm{a}, *}$, J. Chioua $^{\mathrm{b}}$, J. Romero ${ }^{\mathrm{c}}$, A. Vázquez $^{\mathrm{c}}$, D. Macías ${ }^{\mathrm{d}}$, C. Dastis ${ }^{\mathrm{a}}$, E. Ramírez-Romero ${ }^{\mathrm{e}}$, F. Echevarria $^{\mathrm{e}}$, \\ J. Reyes ${ }^{c}$, C.M. García ${ }^{\mathrm{e}}$ \\ ${ }^{a}$ Centro Andaluz de Ciencia y Tecnología Marinas (CACYTMAR), Universidad de Cádiz, Campus de Puerto Real S/N, Puerto Real, 11510 Cádiz, Spain \\ ${ }^{b}$ Institut National de Recherche Halieutique, Centre Régional de Tanger, 5268, Dradeb 90000, Tanger, Morocco \\ ' Departamento de Física Aplicada, Universidad de Cádiz, Avda República Saharaui S/N, Puerto Real, 11510 Cádiz, Spain \\ ${ }^{\mathrm{d}}$ Instituto de Ciencias Marinas de Andalucía, Consejo Superior de Investigaciones Científicas, Puerto Real, 11510 Cádiz, Spain \\ e Departamento de Biología, University of Cadiz, Puerto Real, 11510 Cádiz, Spain
}

\section{A R T I C L E I N F O}

\section{Article history:}

Received 10 January 2013

Received in revised form 2 June 2013

Accepted 8 June 2013

Available online 27 June 2013

\begin{abstract}
A B S T R A C T
This article presents a detailed analysis of the sub-mesoscale transport processes in the Strait of Gibraltar. The interest is focussed on the Camarinal Sill region, and special attention is paid to the across-strait transport processes, the divergences and convergences in the central zone, and the small-scale circulation patterns along the northern coastal margin. The analysis is based on high-resolution (7 m) SST images acquired by an air-borne hyper-spectral scanner, and has been complemented with a rhodamine-release experiment, continuous thermo-salinograph records, acoustic Doppler current (ADCP) profiles from both moorings and vessel-mounted experiments, and numerical modelling. It is deduced from the analysis that the coupling between the upwelling processes, induced by the internal tide and the generation of large-amplitude internal waves, and the cyclonic eddies formed on the coastal margin, seems to be the mechanism that explains the chlorophyll maxima frequently found on the coastal margin of the studied area. Further, as a consequence of the small-scale patterns of circulation induced by the internal waves, the suspended substances are displaced from the coastal margins toward the central zones and later are carried by the westward current toward the convergence zones created by the internal waves, where they may be retained and accumulate. Then, in the eastward phase of the tidal current over the Camarinal Sill, these nuclei of concentrated substances (nutrients, chlorophyll, and plankton) are transported toward the Alboran Sea, where they must contribute, in part, to the primary productivity there.
\end{abstract}

(c) 2013 Elsevier Ltd. All rights reserved.

\section{Introduction}

The Strait of Gibraltar is the Mediterranean's only communication with the world ocean, hence its significance. The Strait is about $60 \mathrm{~km}$ long, $15 \mathrm{~km}$ wide at its narrowest section (the Tarifa narrows) and only $280 \mathrm{~m}$ deep at its main sill (Fig. 1). Bottom topography highlights the existence of two sills: the main sill, known as the Camarinal, is very shallow and defines the very short section that acts as a bottleneck for water exchange between the basins; the second, the Spartel Sill, is deeper and situated to the west in the channel that runs in a southerly direction along the Majuan ridge, by which the greater part of the Mediterranean water inflow and outflow takes place. Located between the two sills is the Tangier basin (with a maximum depth of over $600 \mathrm{~m}$ ), which is a small reservoir of considerable significance for tidal dynamics. To the east of Camarinal Sill, the bottom drops sharply to a depth of $900 \mathrm{~m}$ on the eastern side of the Strait.

\footnotetext{
* Corresponding author. Tel.: +34 956016498; fax: +34 956016079.

E-mail address: miguel.bruno@uca.es (M. Bruno).
}

There are four main components to the flow (Candela, 1991): first, a tidal, mainly barotropic flow, with magnitudes of up to $2.5 \mathrm{~ms}^{-1}$ (Candela et al., 1990); second, a barotropic subinertial component (with periodicity ranging from days to several months) driven by atmospheric pressure fluctuations within the Mediterranean, and with magnitudes close to $0.4 \mathrm{~ms}^{-1}$ (Candela et al., 1989); third, a long-term baroclinic component driven by the internal pressure gradient due to the density difference between the Mediterranean and the Atlantic Waters, with magnitudes of about $0.5 \mathrm{~ms}^{-1}$ (Bryden et al., 1994); and fourth, shorter-than-tidal period currents associated with large-amplitude internal waves induced by the interaction of tidal flows with vertical stratification and bottom topography, which are mainly generated near the Camarinal Sill (Armi and Farmer, 1988; La Violette and Arnone, 1988; Richez, 1994; Bruno et al., 2002; Alonso del Rosario et al., 2003; Vázquez et al., 2008). Therefore, in physical terms, the Strait is a very energetic system with long-term, subinertial, tidal and super-tidal currents all being of significant amplitude.

In biogeochemical terms, the large-amplitude internal wave phenomena are of special relevance because they have been found 

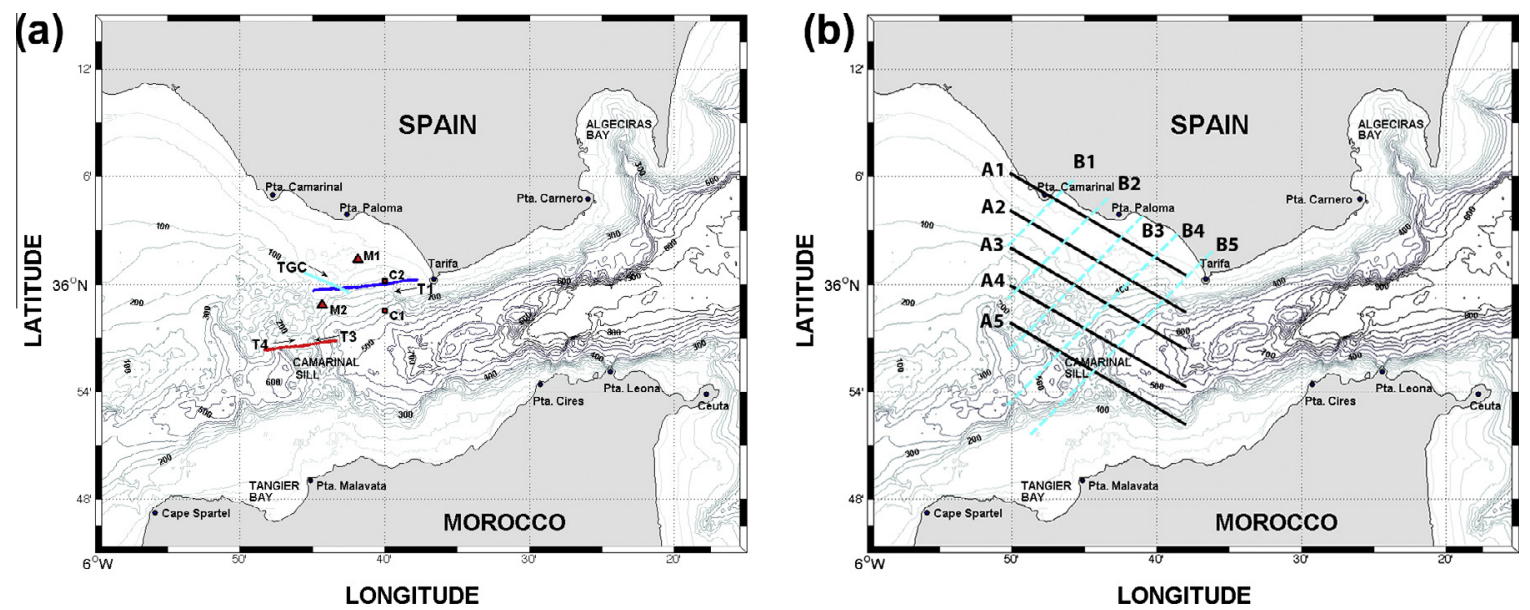

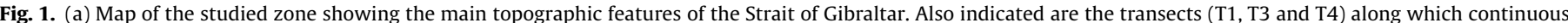

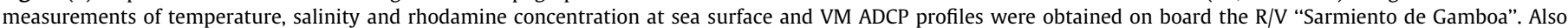

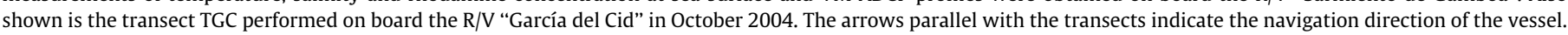

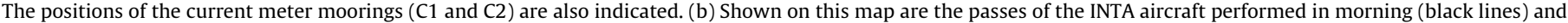
evening (dashed cyan lines) flights on September 17th 2008, to acquire SST images with the AHS scanner.

to be one of the major contributors to the mixing between the Atlantic and Mediterranean layers within the Strait (Wesson and Gregg, 1994; Macías et al., 2006), and they are capable of exerting significant remote effects on the hydrography of the Alboran Sea (Vázquez et al., 2006). These characteristics make it especially important to study internal wave phenomena in the Strait of Gibraltar.

As discussed in Vázquez et al. (2008), the trapping of internal waves on the lee side of the Sill is caused by the establishment of critical or supercritical conditions over the Sill, and this is an important factor explaining the increase in amplitude that internal waves experience there. The release of the internal waves towards the Mediterranean begins with the establishment of subcritical conditions over the Sill. This happens almost at the start of the eastward phase of the barotropic tidal currents.

Macías et al. (2006) reported the cyclic (at semidiurnal period) arrival of nuclei with a high concentration of chlorophyll at the eastern side of the Strait, which would seem to be associated with the internal wave occurrences. Later Macías et al. (2007) used a 1D coupled hydrodynamics-biology model to show that the chlorophyll pulses and general abundance of phytoplankton observed at the eastern entrance to the Strait could not be explained by the growth of these organic materials in the surface water transported towards the Mediterranean by the Atlantic inflow, because their residence time within the Strait is too short for this to occur. Macías et al. (2008) also analysed the observations of the chlorophyll maxima reported in the central zone of the Strait and found the so-called "suction maxima". This designation was based on the percentage of larger cells and active chlorophyll present in these "maxima"; this was also indicative of a coastal origin, as larger cells are generally found in coastal environments. The presence of certain picoplankton species such as Synechococcus also reinforces that idea.

Those findings led to the hypothesis that the phytoplankton growth processes and the retention of phytoplankton in hydrodynamic structures at the coastal margins of the Strait must be taken into account for a proper understanding of the biological variables and distributions in the Strait of Gibraltar area. That hypothesis has recently been confirmed by Vázquez et al. (2009) who analysed satellite images of chlorophyll and have shown that, during the flood tide (westward tidal flow), the establishment of large-amplitude internal waves generated on the lee side of Camarinal sill seems to induce a suction of chlorophyll-rich water masses from the coastal margins toward the central zones of the channel.

However, the causes of the high chlorophyll concentration at the coastal margin of the eastern part of the strait remain unexplained. To date, there have been no studies carried out based on in situ measurements of those suction processes, other than those using the satellite images. In the present article we will try to fill the existing gaps in knowledge of the mechanisms driving these transport processes. This objective is made possible by using an air-borne hyper-spectral scanner which has enabled high spatial resolution images of the studied area to be acquired, before and after the time of the internal wave generation. The study is aided by other techniques, including tracking the concentration of rhodamine as it spreads from a specific point of release on the coastal margin, continuous thermosalinograph measurements, acoustic Doppler current (ADCP) profiles from both moorings and vesselmounted experiments, and numerical modelling.

The manuscript is structured in four sections. In the following part the methodology used for the analysis and the data set used are described. The third section presents the main results, which are discussed in the fourth section. Finally the main conclusions of the study are drawn in the last section.

\section{Applied methodology and data in use}

The methodology used in the study is based on the following types of data:

(I) High-resolution (7 m) SST images acquired by an Airborne Hyper-spectral Scanner (AHS) provided by the Spanish Institute of Aerospace Techniques (INTA).

(II) Measurements made along vessel transects crossing the studied zone, of current velocity and echo-intensity profiles acquired by ADCP, and sea surface temperature, salinity and released rhodamine (see Fig. 1).

(III) Several conductivity, temperature and depth (CTD) profiles taken at selected points within the region of the Camarinal Sill.

(IV) Current velocity time-series recorded at two mooring placements within the studied zone (see Fig. 1).

(V) Numerical modelling of the tidal-induced hydro-dynamics. 
The most of the data used in the study have been collected during the oceanographic campaign "GIBRALTAR 2008" carried out onboard the R/V 'Sarmiento de Gamboa' during September and October 2008. The data used in this article were collected on September 17th 2008, in spring tides conditions, when the largest amplitude internal waves in Camarinal Sill are generated. As complementary information, we also make use of ADCP measurements taken onboard the R/V 'García del Cid' during a survey carried out in October 2004, and some satellite images of sea surface temperature and chlorophyll.

\subsection{High resolution SST images acquired by the air-borne AHS scanner}

As part of the aforementioned campaign, four flights were made over the studied zone with the aircraft Paternina (CASA 212-200), provided by the INTA, porting an AHS scanner, on September 17th and 19th 2008. Flights were spread over two days, two per day. On each day one of the flights was made at the time of the start of the westward phase of the tidal current, and the other at the time of maximum westward tidal current. These times and locations were chosen in order to track the changes in the sea surface temperature (SST) induced by the internal wave phenomena that are generated around the Camarinal Sill in the westward phase of the tidal current. The SST images have a spatial resolution of about $7 \mathrm{~m}$. Details of the image acquisition procedure are shown in Tables 1 and Fig. 1. In order to minimise the effect of light reflections from the sea surface on some bands of the electromagnetic spectrum received by the AHS radiometer, the different passes of the flights were performed in a different direction according to the position of the sun. From each pass an image band of $5 \mathrm{~km}$ width was acquired, with an overlap of $2 \mathrm{~km}$ between bands.

\subsection{Measurements onboard the vessel}

In order to collect in situ evidence of the exchange processes taking place between the central zone of the Strait and the coastal margin between Punta Camarinal and Punta Tarifa (see map in Fig. 1), an experimental design of measurements was devised. As a first element of the experiment, a volume of rhodamine was released, with the assistance of a small boat, at a point on the coastal margin. Later the rhodamine concentration at the sea surface was recorded from the RV 'Sarmiento de Gamboa' while following the track shown in Fig. 1. The ship moved along this zigzag line during $18 \mathrm{~h}$ on September 17 th 2008 , i.e. covering an entire tidal cycle. Note that transect $\mathrm{T} 1$ and flight 1 start at the same time. Water was collected through a surface intake (nominal depth $5 \mathrm{~m}$ ) and conducted to the recording chamber of the fluorometer which recorded rhodamine-related fluorescence at $1 \mathrm{~Hz}$ rate. Data were stored in the fluorometer-physical memory and later downloaded to a compatible PC computer.

\section{Table 1}

Information about the flight 1 (Panel a) and flight 2 (Panel b) carried out to acquire the SST images with the airborne AHS scanner on September 17th 2008.

\begin{tabular}{lllll}
\hline Track & Time (UTC) & Altitude $(\mathrm{m})$ & Heading $(\mathrm{deg})$ & Length/duration \\
\hline Flight 1 & & & & \\
A1 & $8: 36$ & 2751 & 300 & $21 \mathrm{~km} / 4 \mathrm{~min} 52 \mathrm{~s}$ \\
A2 & $8: 49$ & 2751 & 120 & $21 \mathrm{~km} / 4 \mathrm{~min} 52 \mathrm{~s}$ \\
A3 & $8: 59$ & 2751 & 300 & $21 \mathrm{~km} / 4 \mathrm{~min} 52 \mathrm{~s}$ \\
A4 & $9: 09$ & 2751 & 120 & $21 \mathrm{~km} / 4 \mathrm{~min} 52 \mathrm{~s}$ \\
A5 & $9: 20$ & 2751 & 300 & $21 \mathrm{~km} / 4 \mathrm{~min} 52 \mathrm{~s}$ \\
Flight 2 & & & & \\
B1 & $13: 13$ & 2751 & 225 & $10 \mathrm{~km} / 2 \mathrm{~min} 19 \mathrm{~s}$ \\
B2 & $13: 23$ & 2751 & 45 & $15 \mathrm{~km} / 3 \mathrm{~min} 28 \mathrm{~s}$ \\
B3 & $13: 34$ & 2751 & 225 & $20 \mathrm{~km} / 4 \mathrm{~min} 38 \mathrm{~s}$ \\
B4 & $13: 45$ & 2751 & 45 & $25.4 \mathrm{~km} / 5 \mathrm{~min} 53 \mathrm{~s}$ \\
B5 & $13: 57$ & 2751 & 225 & $27 \mathrm{~km} / 6 \mathrm{~min} 15 \mathrm{~s}$ \\
\hline
\end{tabular}

The precise moment for the release of the tracer was selected to be just at the start of the westward phase of the tidal current, as the large-amplitude internal wave was beginning to be generated, when the possible suction processes powered by the internal waves are expected to take place. This continuous record of rhodamine concentration was accompanied by the continuous record of profiles acquired by a $75 \mathrm{kHz}$ VM-ADCP, at a sampling rate of $1 \mathrm{~min}$, and sea surface temperature and salinity taken at the same sampling rate. VM-ADCP measurements taken onboard the R/V 'García del Cid' during a survey carried out during October 2004 are used as auxiliary information. The location of the measurement transects is indicated in Fig. 5, and detailed information about their date and time is given in Table 2 .

\subsection{Current velocity measurements from moored instruments}

To get an adequate description of the current velocity variability in the across-strait dimension, two current meter moorings were deployed, one ADP profiler at the northern coastal margin, at a bottom depth of $24 \mathrm{~m}$, and a mooring line with three one-point current meters (at depths of 60,100 and $150 \mathrm{~m}$ ), at a bottom depth of $180 \mathrm{~m}$, in the northern part of Camarinal Sill. In Table 3 detailed information is given about these moorings, and in Fig. 1 their positions are indicated. Due to an incorrect installation of the ADP on the northern coast, a new deployment of this instrument was needed. For this reason the record of current in that position is not coincident with the onboard measurements. In order to get tidal currents at the northern coastal margin, they had to be synthesised on the basis of the previously-computed tidal harmonic constants. In Table 4 the harmonic constants obtained at $12 \mathrm{~m}$ depth are given.

Table 2

Information about the measurement transepts performed onboard the RV "Sarmiento de Gamboa" on September 17th 2008.

\begin{tabular}{lllllll}
\hline Transept & Start & $\begin{array}{l}\text { Initial } \\
\text { longitude }\end{array}$ & $\begin{array}{l}\text { Initial } \\
\text { latitude }\end{array}$ & End & $\begin{array}{l}\text { Final } \\
\text { longitude }\end{array}$ & $\begin{array}{l}\text { Final } \\
\text { latitude }\end{array}$ \\
\hline T1 & $8: 59$ & -5.628843 & 36.003258 & $10: 06$ & -5.749238 & 35.993462 \\
T3 & $11: 54$ & -5.721162 & 35.947971 & $12: 34$ & -5.805291 & 35.938793 \\
T4 & $12: 36$ & -5.802262 & 35.938721 & $12: 58$ & -5.758095 & 35.942280 \\
\hline
\end{tabular}

Table 3

Information about the currentmeters line and current meter profiler moored in the survey.

\begin{tabular}{lllllll}
\hline Mooring & Start & End & $\begin{array}{l}\text { Record } \\
\text { length } \\
\text { (days) }\end{array}$ & $\begin{array}{l}\text { Longitude } \\
\text { E (deg) }\end{array}$ & $\begin{array}{l}\text { Latitude } \\
\text { N (deg) }\end{array}$ & $\begin{array}{l}\text { Sampling } \\
\text { interval } \\
\text { (min) }\end{array}$ \\
\hline M1 & $7 / 1 / 2009$ & $21 / 4 / 2009$ & 104 & -5.6970 & 36.0232 & 2 \\
M2 & $15 / 9 / 2008$ & $15 / 10 / 2008$ & 28 & -5.7385 & 35.9809 & 5 \\
\hline
\end{tabular}

Table 4

Harmonic constant of the predominant current velocity at $12 \mathrm{~m}$ depth recorded by currenmeter profiler moored in the location M1 (see map of Fig. 1).

\begin{tabular}{llc}
\hline Tidal constituent & Amplitude $(\mathrm{m} / \mathrm{s})$ & Greenwich phase $(\mathrm{deg})$ \\
\hline $\mathrm{Z}_{0}$ & 0.3423346 & 0.0000 \\
O1 & 0.1566557 & 343.328 \\
K1 & 0.1080618 & 61.129 \\
N2 & 0.1816619 & 86.887 \\
M2 & 0.9943704 & 113.178 \\
S2 & 0.3935287 & 148.443 \\
M4 & 0.0405051 & 91.508 \\
\hline
\end{tabular}




\subsection{Numerical model experiments}

Experiments with a numerical model have been conducted to investigate the small-scale hydrodynamic features at the coastal margins, and their role in explaining the higher chlorophyll concentration in those zones. The model is a 2D, nonlinear, two-layer, free-surface, hydrostatic model with boundary-fitted curvilinear coordinates. Sea-water density is uniform and prescribed in each layer. A complete description of the model, including governing equations and parameter values used, can be found in Izquierdo et al. (2001).

The model is forced at the open boundaries with radiation-type boundary conditions ensuring that, when short-wavelength disturbances in the fields of variables are generated, they all propagate away from the region of interest. At the coastal boundaries a condition of null normal flow is applied. In order to reduce the influence of any inaccuracies in boundary forcing on the required solution, the waves produced within the strait are allowed to propagate freely through its open boundaries. The staggered Arakawa- $\mathrm{C}$ curvilinear grid has a default resolution of $1.0 \mathrm{~km}$ decreasing to $0.125 \mathrm{~km}$ in the Strait of Gibraltar, with a total of $198 \times 40$ grid cells.

The $\mathrm{M}_{2}, \mathrm{~S}_{2}, \mathrm{~K}_{1}$ and $\mathrm{O}_{1}$ surface tidal elevation amplitudes and phases used to set the tidal forcing at the open boundary grid points were derived by interpolating the relevant values from a 0.5 degrees gridded version of the FES95.2 global tidal solutions of Le Provost et al. (1998). The initial mean interface depth was taken from the solution to the 2D steady, two-layer exchange flow problem in the Gulf of Cadiz-Strait of Gibraltar-Alboran Sea system given in Sein et al. (1998). The bathymetry was obtained from the ETOPO5 database, complemented by the data from the comprehensive chart published by Instituto Geográfico Nacional and
SECEG (1988). The model was run for 30 identical semidiurnal tidal cycles to achieve a stable time-periodic solution.

\section{Results}

In this section we will present the results obtained from the application of the proposed analysis methodology. The presentation of results will centre on the high-resolution SST images acquired by the AHS scanner, to aid the interpretation of the thermal structures induced at the northern coastal margin by the dynamics of the central zone of the Strait.

\subsection{Air-borne acquired SST images}

Figs. 2 and 3 show two SST images constructed with the infrared channels of the airborne AHS scanner. The images correspond to two different flights. The first flight took place shortly before the establishment of the westward phase of the tidal current, while the second took place shortly after the occurrence of the maximum tidal current in the westward direction. It should be noted that the large-amplitude internal waves are generated during the westward phase of the tidal current; therefore an appreciable change was expected in the SST small-scale features during the second flight.

As can be appreciated in these figures, during the first flight the colder waters are constrained to the coastal margin and the warmer water occupies the central zone of the channel. There is also a pool of cold water that seems to be trapped within an eddy created during the eastward phase of the tidal current. In contrast, during the second flight, a short time after the maximum westward tidal current was reached, it is observed that the colder coastal waters between Punta Camarinal and Punta Paloma seem to
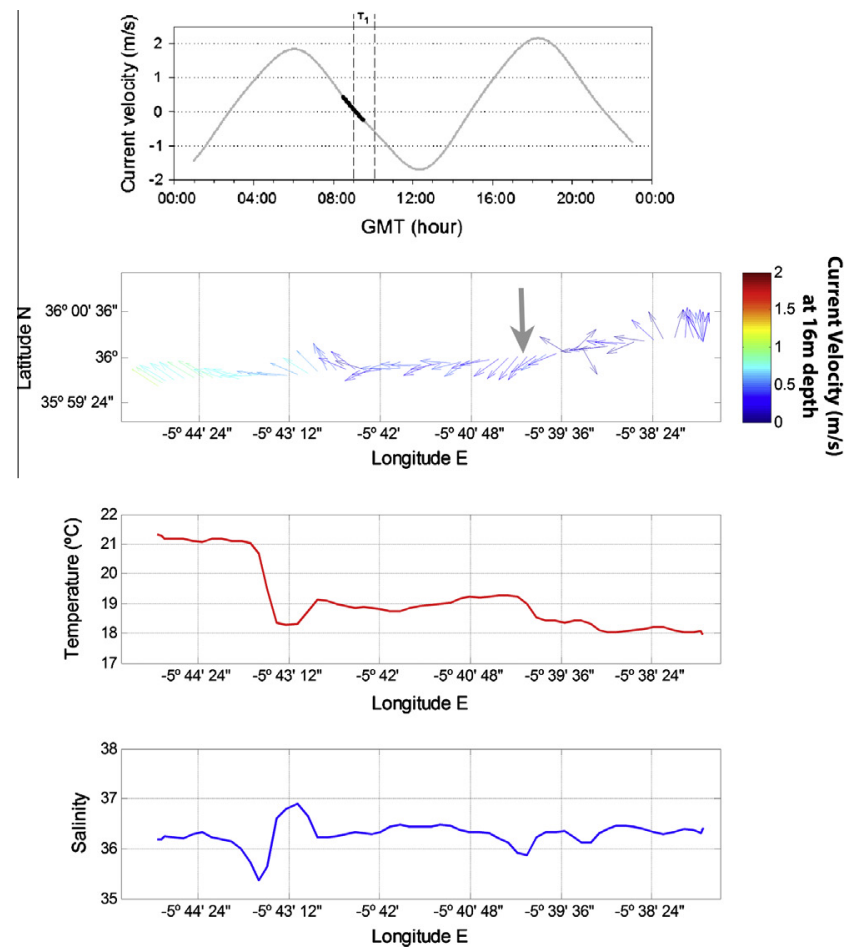
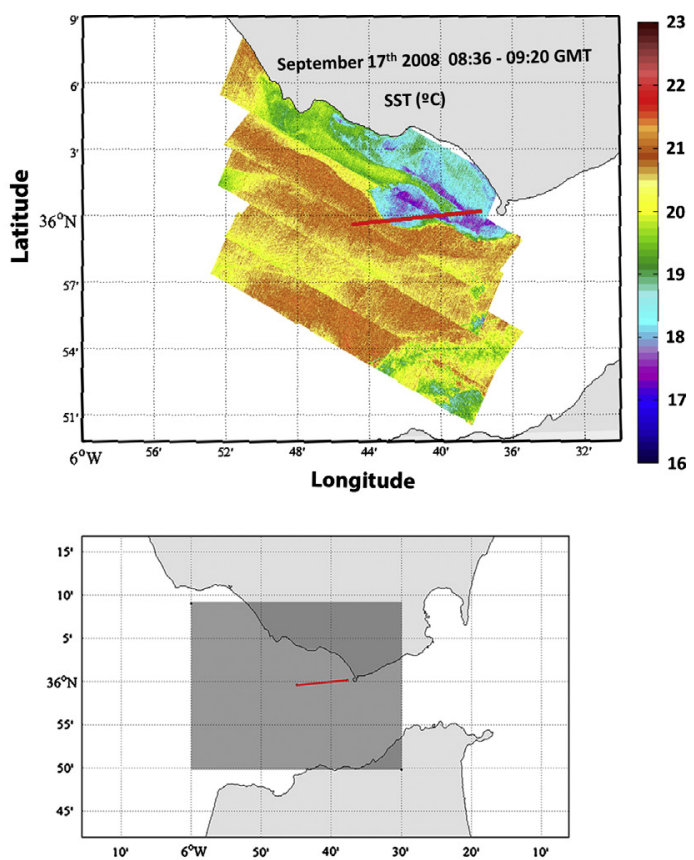

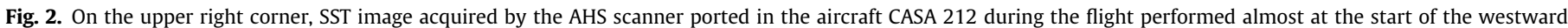

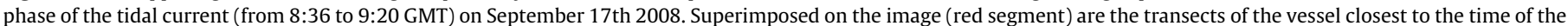

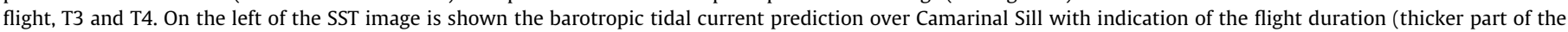

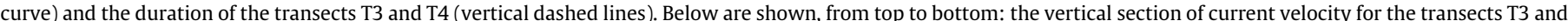

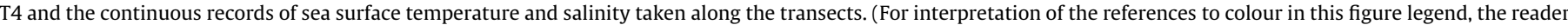
is referred to the web version of this article.) 

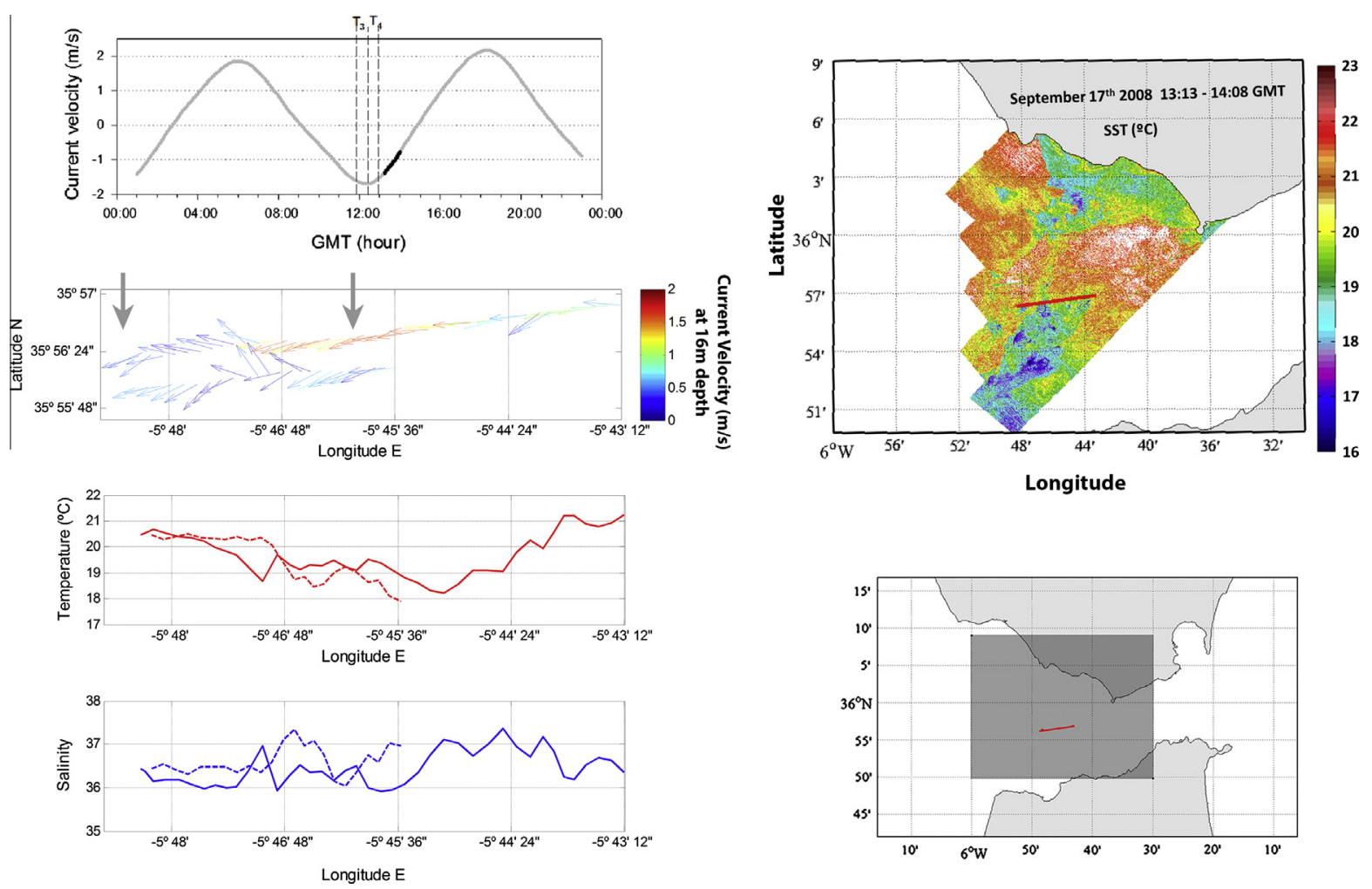

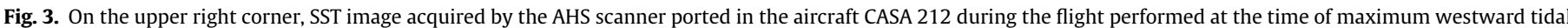

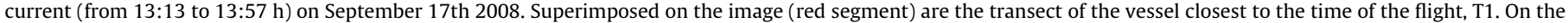

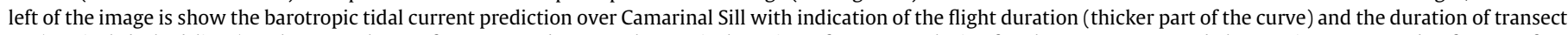

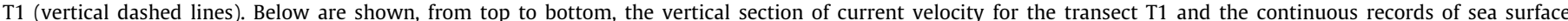

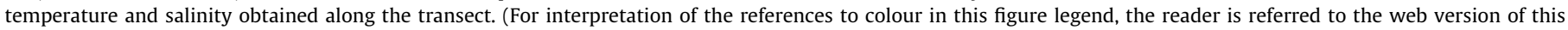
article.)

develop some elongated patches of cold water that extend towards the central zone of the Strait.

\subsection{Measurements made onboard the vessel}

The salinity and temperature profiles obtained over the Camarinal Sill region in two CTD casts are shown in Fig. 4: one at the finish of the westward phase of tidal current (C1) and the other very close to the moment of maximum eastward tidal current (C2). We can observe that, during the westward phase, the depth of the Atlantic-Mediterranean Interface (AMI), usually assigned to the depth of the 37.5 isohaline in the Camarinal sill area (GarcíaLafuente et al., 2002), has risen above the $50 \mathrm{~m}$ depth level. Considering that the CTD stations are close to the coast, it is considered inevitable that AMI water would periodically be distributed along the coastal margin, bringing more salty and colder waters to those parts. This kinematic effect of the AMI could explain the pool of colder water constrained in the coastal area between the Camarinal Sill and Punta Tarifa, recorded in the high resolution SST image acquired by the airborne AHS scanner during the first flight, shortly before the start of the westward phase of the tidal current.

Some evidence of this cross-strait transport may be observed in the current velocity records taken by the VM-ADCP (at $16 \mathrm{~m}$ depth) during the first longitudinal transect ( $\mathrm{T} 1$ in Fig. 2), the closest in time to the first flight and performed when westward phase of the tidal current was starting to take place. In particular, between the longitudes $-5^{\circ} 39^{\prime} 36^{\prime \prime}$ and $-5^{\circ} 40^{\prime} 48^{\prime \prime} \mathrm{E}$, current velocity at $16 \mathrm{~m}$ depth shows a clear southwest component. SST records, obtained by the thermo-salinograph on the vessel, confirm the AHS images locating the colder waters in the easternmost part of the transect. The sea surface salinity records obtained onboard also show values slightly higher than those of the Atlantic Surface Water, which may be indicative of the presence in these coastal waters of some contribution of up-welled AMI water. Note that on the westernmost side of the transect very low salinity and high temperature values are recorded, which could indicate the presence of coastal waters, not containing the colder AMI waters, being transported westward.

Shown in Fig. 3 are the records acquired during the performance of the transects T3 and T4. These transects are the closest in time to the second flight, and were performed during the westward phase of the tidal current. The recorded sea surface variables show, as a general feature, colder and saltier water toward the western side of the transect. This feature is related to the AMI rising to shallower depths during this tidal current phase, and the subsequent mixing of the AMI waters with upper layer waters. Although a considerable proportion of the cold waters in the upper layer must originate from the AMI, evidence can be found for water coming from the coastal margin contributing to this cold pool, as shown in the transect T4 where a mass of slightly warmer and less salty water is moving with a clear southward component between the longitudes $-5^{\circ} 45^{\prime} 36^{\prime \prime}$ and $-5^{\circ} 46^{\prime} 30^{\prime \prime} \mathrm{E}$.

To obtain more detailed evidence of the change in the current direction near the coastal margin around Punta Paloma, we use the ADCP measurements made in several consecutive transects by the R/V "García del Cid" during a survey carried out in October 2004. The current velocity measurements at $12.5 \mathrm{~m}$ depth along consecutive transects made during the westward phase of the tidal current are shown in Fig. 5. It can be observed how the current velocity near to the coastal margin increases its southward component, when the westward component of the tidal current over the Camarinal Sill is intensified. Note that the southward component is more marked in the westernmost part of the transects. 

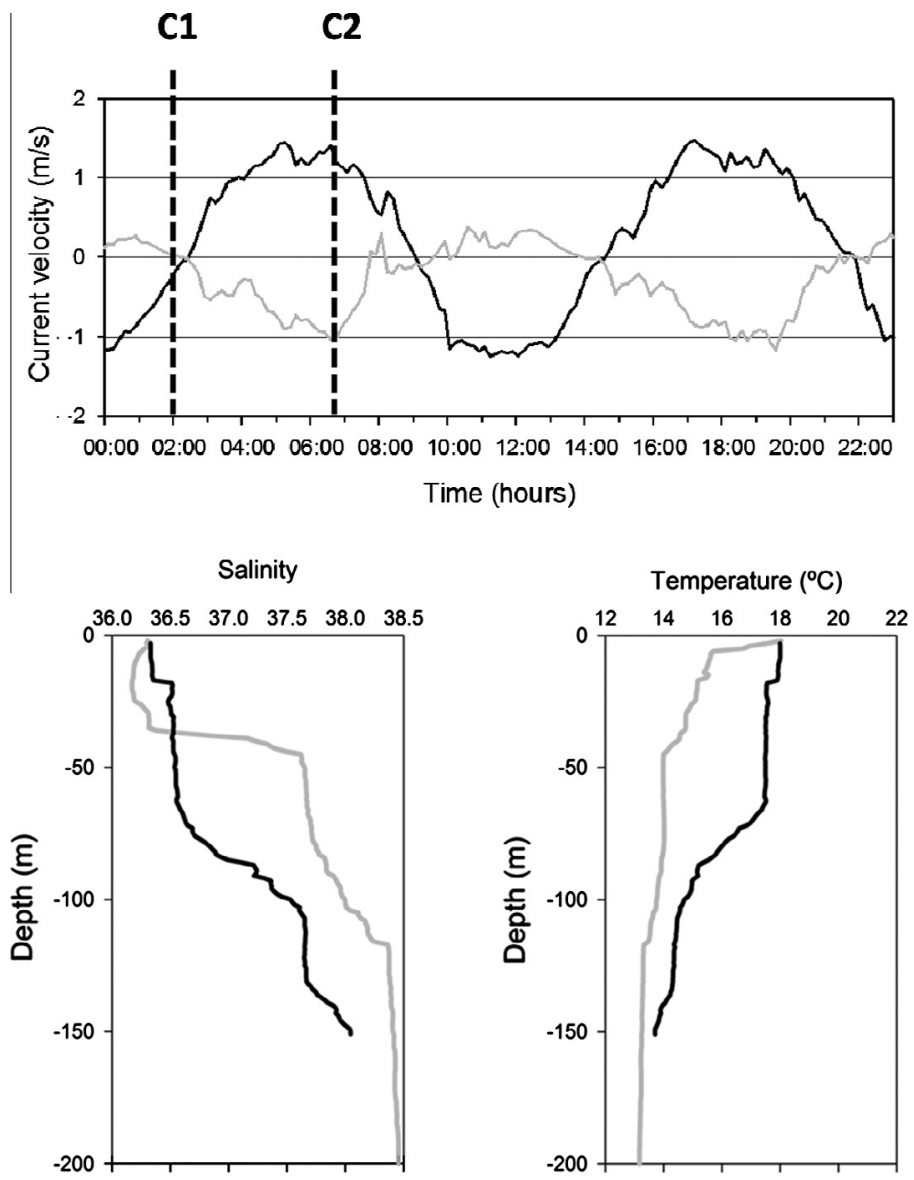

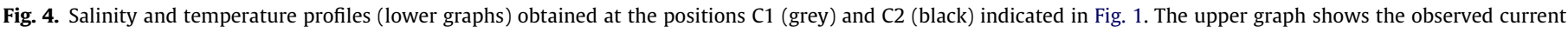

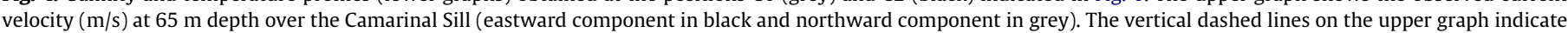
the times when each profile was obtained.

As explained above, the rhodamine was released shortly before the tidal current reversion over the Camarinal Sill (from an eastward to a westward direction). Coinciding with the release, the vessel started recording the surface rhodamine-fluorescence along the sampling path beginning at the north-east corner (see Fig. 6). As can be observed, in the south of the sampling area no rhodamine was detected, at this stage, the recorded concentrations were very close to the threshold for analytical determination (situated at $0.1 \mathrm{ppb}$ ). As the vessel sailed further off-shore, the rhodamine concentration detected increases progressively, particularly on the western side of the middle transect and in the region closest to the release area.

Considering that the distance between the point of release of rhodamine and the first transect was about $2.0 \mathrm{~km}$, from the time of the release (8:30 UTC) and the time when the presence of rhodamine was detected on the transect (9:50 UTC), a minimum across-strait current intensity of $0.6 \mathrm{~m} / \mathrm{s}$ can be estimated. The accuracy of this estimate may be checked by examining the tidal current behaviour at the coastal margin at the time when the rhodamine was released.

Fig. 7 shows the current velocity records at a depth of $65 \mathrm{~m}$ over the northern part of the Camarinal Sill, obtained at position M1 (see map of Fig. 1) together with the tidal current prediction for the same time at a depth of $12 \mathrm{~m}$, at the position of mooring $\mathrm{A}$ (Punta Paloma), which coincides with the position of the release point. At the time of the rhodamine release, 8:30 GMT, it can be seen that the currents at the mooring A were in a south-easterly direction, at a velocity of about $0.75 \mathrm{~m} / \mathrm{s}$; this explains the detection of the rhodamine along the transect at 9:50 GMT.
The second sampling leg was begun just at the start of the eastward phase of the tidal current, at the south-western end of the sampling path. Higher concentrations of rhodamine were found in the eastern part of the sampled area, corresponding to a rapid advection of the marked water masses with the increasing eastward flow. At the same time, moderately high concentrations were detected in the middle of the channel of the Strait (at about $35^{\circ} \mathrm{N} 56^{\prime}$ ), thus confirming the 'suction' of coastal waters during the westward phase of the tidal current.

The observations point to the region south of "Punta Paloma" as the area most susceptible to the offshore 'suction' of water masses. This same region has been identified as very relevant for these processes by Vázquez et al. (2009) in a study that combined Advanced Synthetic Aperture Radar (ASAR Image Mode) images and surface colour imagery (MODIS and MERIS sensors). These authors use the remote information from the different sensors to study the generation (and propagation) of several internal waves episodes over the Camarinal Sill and associated 2D surface structures, and relate them to the tidal conditions within the Strait. These studies show the first in situ observations of such interactions between the coastal margin and the dynamics of the central zone of the Strait, and confirm the previous hypothesis and mechanisms proposed in other works.

\subsection{Small-scale circulation patterns over the coastal margin: numerical modelling experiments}

The current velocity field simulated by the numerical model at different moments of the tidal cycle is shown in Fig. 8. Focussing on 

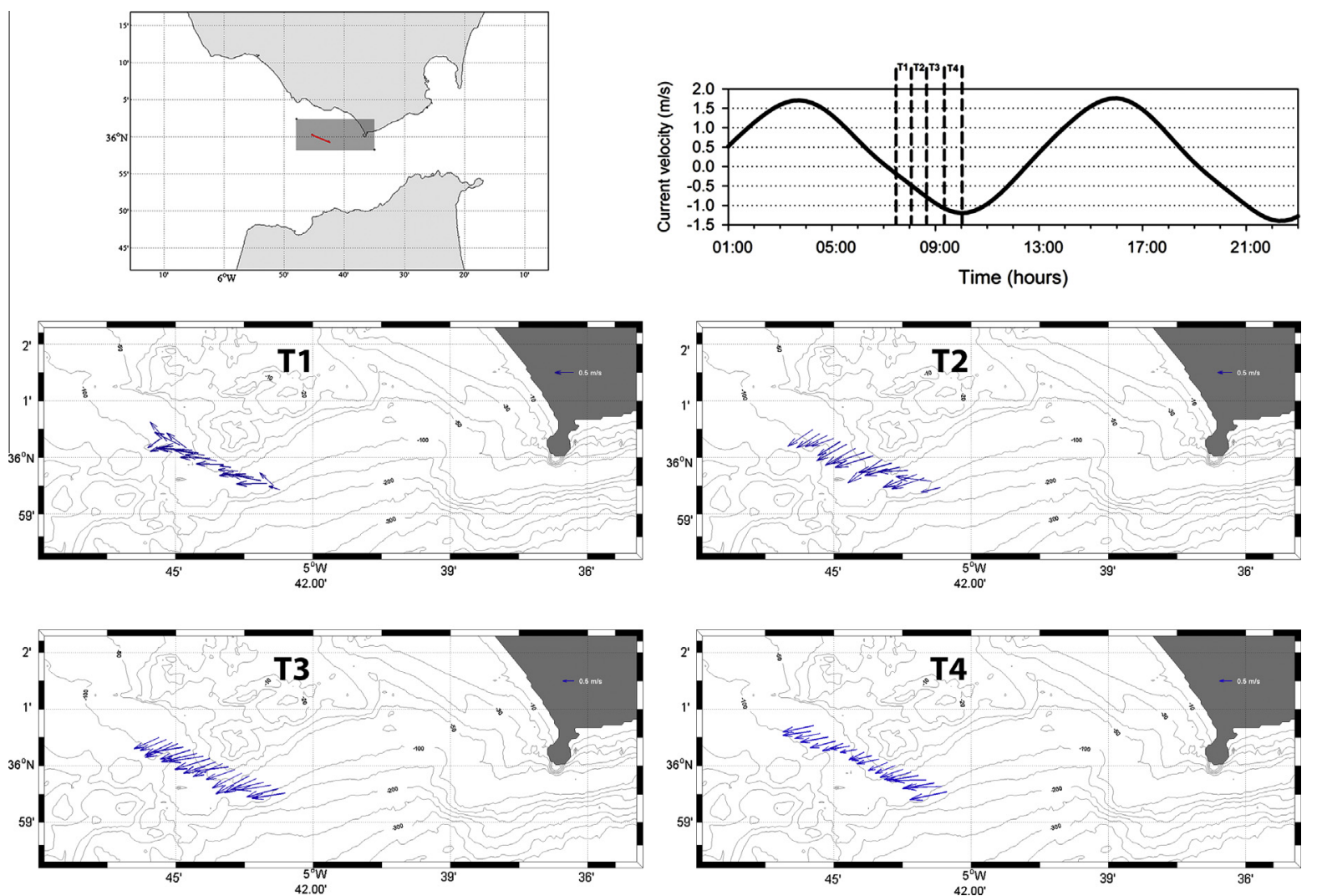

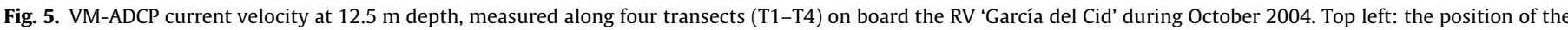
transects. Top right: the current velocity prediction at $45 \mathrm{~m}$ depth over the Camarinal Sill. The vertical dashed lines indicate the time extent of the transects.
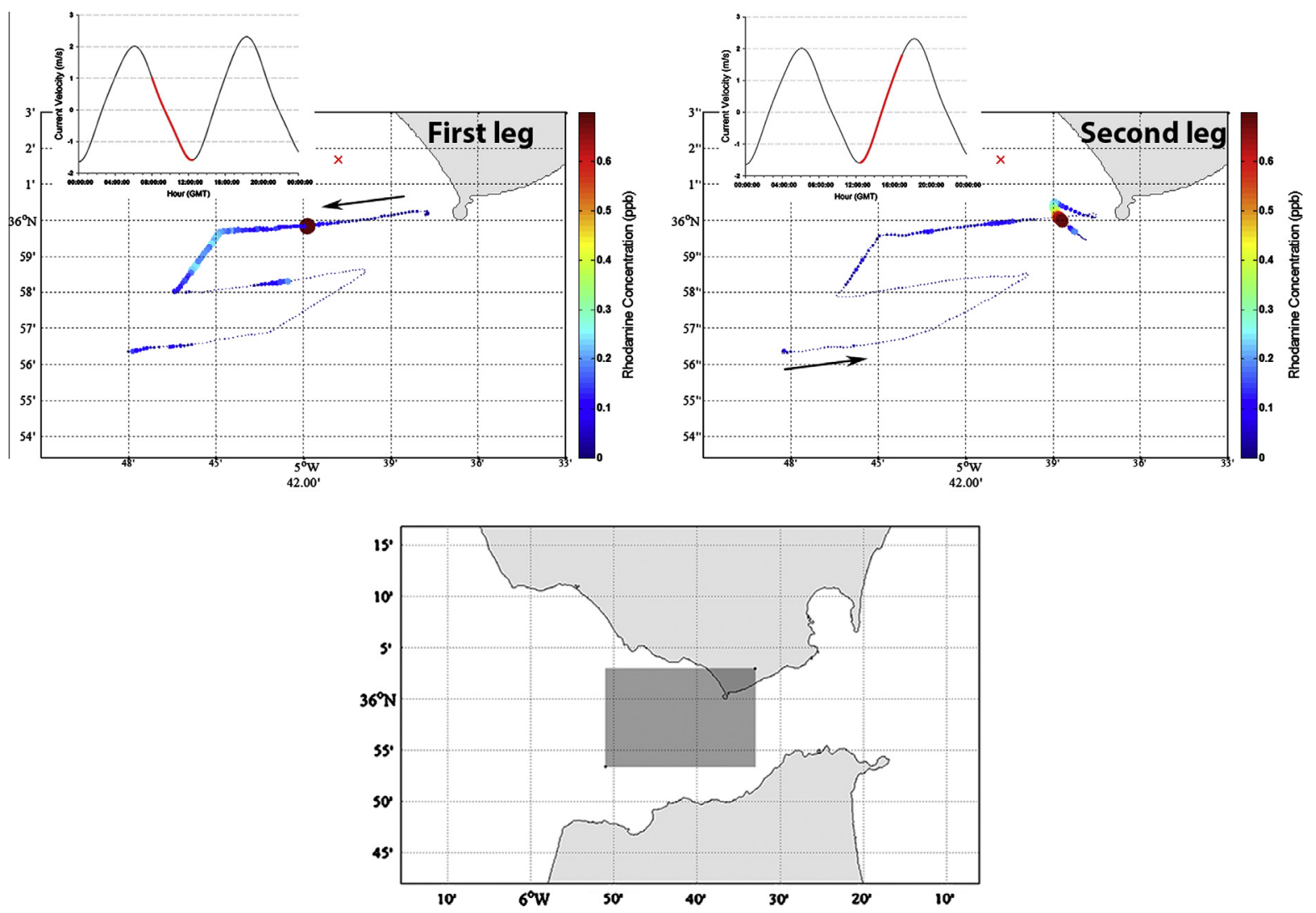

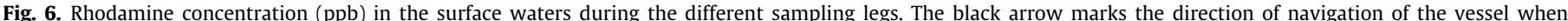

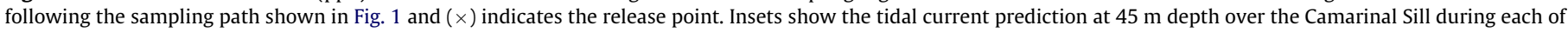
the sampling legs. 


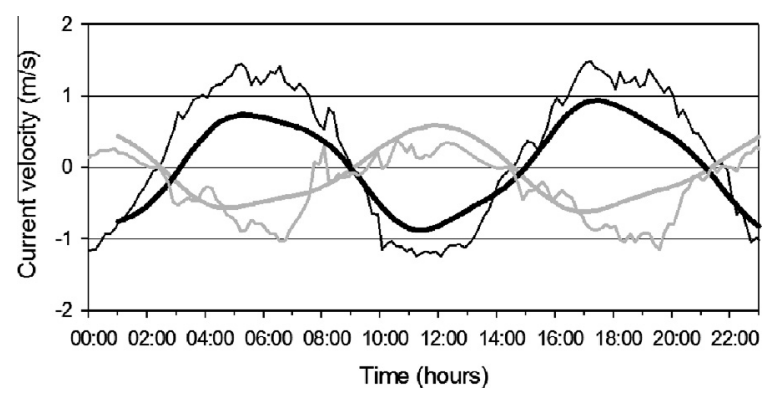

Fig. 7. Time series of current velocity $(\mathrm{m} / \mathrm{s})$. Eastward/northward component in black/grey. Thick lines: predictions at $12 \mathrm{~m}$ depth at the coastal margin near Punta Paloma, at the position M1 (see Fig. 1). Predictions are based on the harmonic constants of Table 4. Thin lines: measurements taken in the northern part of the Camarinal Sill at $65 \mathrm{~m}$ depth, at the position M2 (see Fig. 1). the coastal margin between Punta Camarinal and Punta Tarifa, we can observe how, during the eastward phase of the tidal current, a cyclonic eddy develops a little to the east of Punta Paloma. The simulations correspond to September 17th of 2008, the same day when the onboard observations was taken, under spring tide conditions. From simulations not shown in the present manuscript we have observed that this eddy is formed even under neap tide conditions but having a lesser spatial dimension.

Looking at the bathymetry of the zone (Fig. 9), we can speculate that the eddy formation could be related to the channel located between the bank known as Los Cabezos, and the coast. During the eastward phase, tidal currents are intensified in the channel and, at the same time, the flow veers to the south at the exit of the channel, to displace the strong upper-layer eastward transport taking place over the Camarinal Sill. In turn, the more constrained coastal
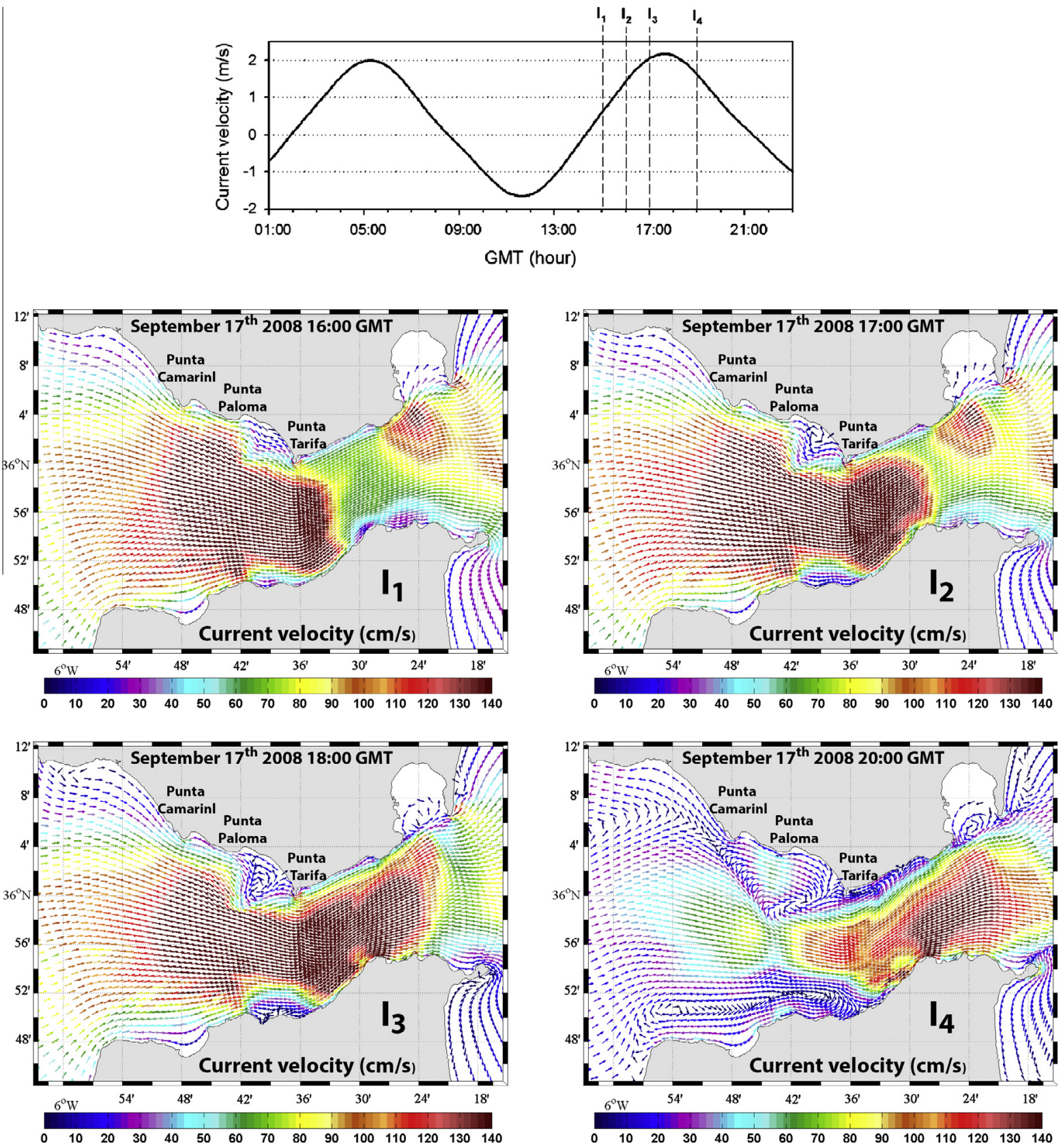

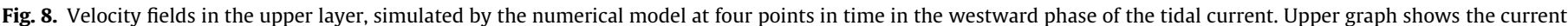

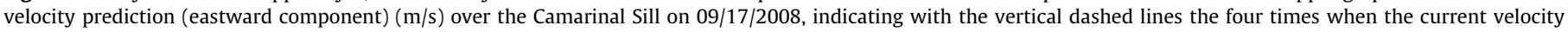
maps were obtained. 


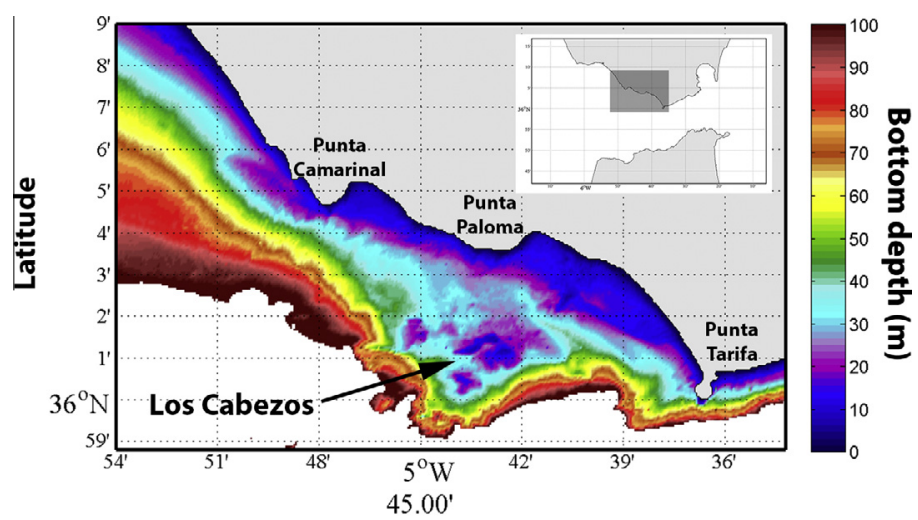

Longitude

Fig. 9. Bathymetry of the coastal margin between Punta Camarinal and Punta Tarifa, with indication of the Los Cabezos bank.

Table 5

Harmonic constant of the predominant current velocity at $60 \mathrm{~m}$ depth recorded by a single-point currentmeter moored in the location M2 (see map of Fig. 1).

\begin{tabular}{llc}
\hline Tidal constituent & Amplitude $(\mathrm{m} / \mathrm{s})$ & Greenwich phase $(\mathrm{deg})$ \\
\hline $\mathrm{Z}_{0}$ & 0.2862 & 0.00 \\
$\mathrm{O} 1$ & 0.1255 & 339.7 \\
$\mathrm{~K} 1$ & 0.1331 & 39.72 \\
$\mathrm{~N} 2$ & 0.1838 & 100.02 \\
M2 & 0.9516 & 123.96 \\
$\mathrm{~S} 2$ & 0.3402 & 129.45 \\
M4 & 0.057 & 62.85 \\
\hline
\end{tabular}

waters between Tarifa and Punta Paloma are moved along and close to coastline, toward the exit of the coastal channel. This pattern would thus enable a cyclonic eddy to form between Punta Paloma and Tarifa. In this way a lower velocity zone is generated that prevents the affected body of coastal water from being 'suctioned' away from the coastal margin by the strong eastward tidal current prevailing in the central zone of the Strait.

It can also be appreciated in the simulated current velocity fields that there is a clear reduction in the tidal current intensity between the coastal margin and the central zone of the Strait. This lower intensity of tidal current at the coastal margin is usually associated with friction effects induced by the shallower bottom and lateral boundaries. This behaviour is in good agreement with the harmonic constant of tidal currents (Tables 4 and 5) corresponding to the moorings M1 (Los Cabezos bank) and M2 (northern part of the Camarinal Sill) which confirm the reduced intensity of the tidal current at the coastal margin.

In order to assess the effect of this tidal current variability on the water mass circulation at the coastal margin, a Lagrangian experiment was designed. This consisted of the release of two
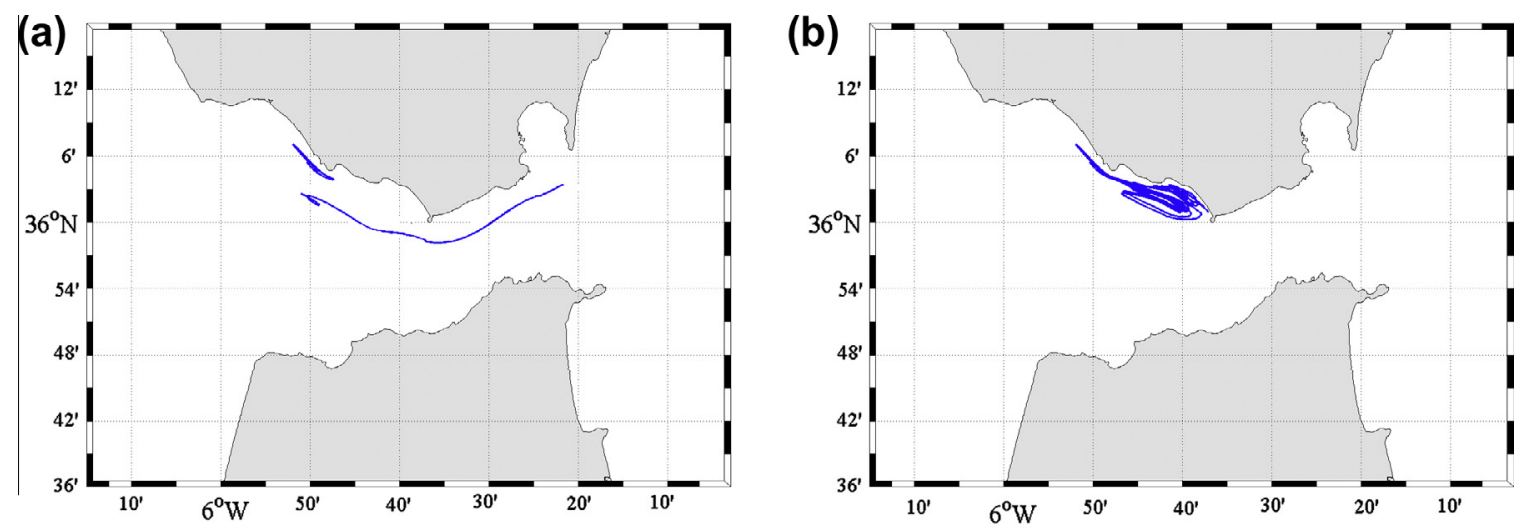

(c)

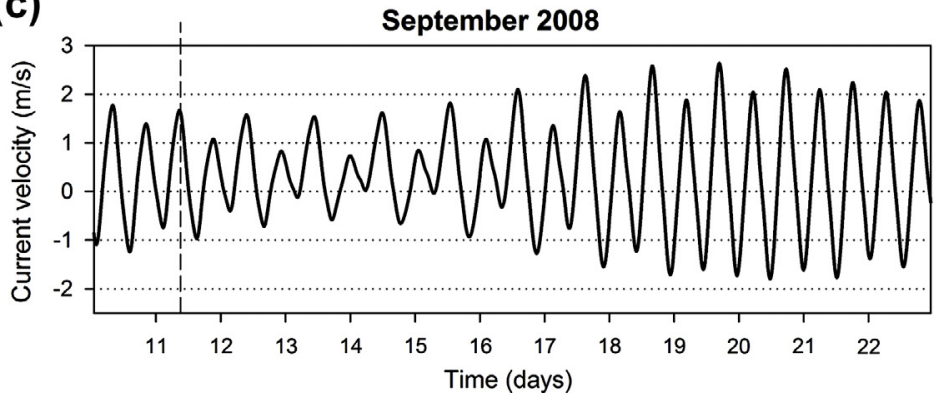

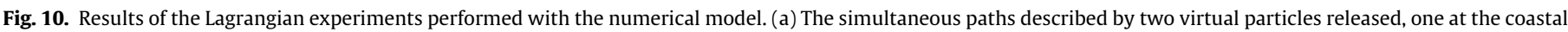

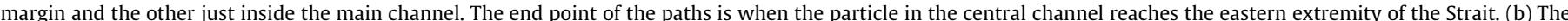

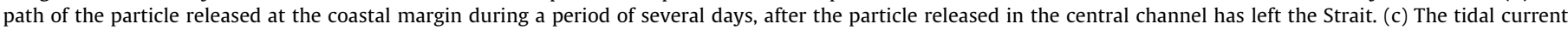
prediction (eastward component) at $45 \mathrm{~m}$ depth over Camarinal Sill, throughout the whole period of the experiment. 
virtual particles: one at the coastal margin and another just in the northern part of the central channel of the Strait. The particles moved under the effects of the tidal current fields simulated by the hydrodynamic model. In Fig. 10 the resulting paths are shown. The virtual particle released in the channel remained there for only 1 day and then entered the Alboran Sea; in contrast, the virtual particle released at the coastal margin stayed in the area of the coastal margin for about 12 days. It should be noted that once the coastal particle reached the area close to Punta Paloma, it stayed for more than 11 days in that area between Punta Paloma and Tarifa. It is reasonable to think that the retention of the virtual particle in this area is due to the action of the cyclonic eddy previously simulated by the hydrodynamic model. This cyclonic eddy may be responsible for the pool of cold water that appears in the high resolution SST images acquired with the AHS scanner during the first flight (which took place shortly before the start of the westward phase of the tidal current).

This extended time of residence of the water masses at the coastal margin, together with the upwelling processes induced by the kinematics of the AMI, which provide nutrient-rich water to these areas, may be the reasons for the high chlorophyll concentration usually found in this zone.

\section{Discussion}

4.1. Interfacial mixing, upwelled waters at the coastal margins and upper-layer divergences and convergences in the central zone of the Strait

Vertical mixing processes around the Camarinal Sill are more active during spring tides in the westward phase of the tidal current (Vázquez et al., 2008). Considering also the large amplitude of the oscillation in the AMI interface depth in the region of the Camarinal Sill (more than $50 \mathrm{~m}$, as can be observed in Fig. 4), a periodic exchange of interface waters between the central zone and the coastal margins must be a very frequent phenomenon. Colder water observed in the coastal area between Punta Paloma and Cape Trafalgar (and shown in the SST satellite images of Fig. 11) supports that idea. If we compare the image acquired just at the start of the westward phase of the tidal current with that acquired during the eastward phase, a clear difference can be appreciated. In the former image colder waters appear very close to the coast line, whereas in the latter image, a general cooling of the upper layer has extended to the whole transversal dimension of the channel and to the eastern side of the Strait. This result is clear evidence of the tidal-related origin of the upwelling phenomena in the Camarinal Sill region.

A more detailed analysis of these upwelling processes has been made by analysing the high resolution SST images obtained with the airborne AHS scanner over the Camarinal Sill area (Figs. 2 and 3). The general cooling of the surface water seen in the image from the first flight is related to the considerable rise of the AMI at the Camarinal Sill and on the eastern side of the Strait, as the westward tidal flow increases. This rising of the interface seems to compensate for the water mass divergence in the upper layer located just to the west of Punta Tarifa, which is the result of the situation whereby the westward tidal current is greater than mean current to the west of Tarifa Point whereas, to the east, it is not so. Consequently, when westward tidal currents reach their maximum, the upper layer currents to the west and to the east of Tarifa Point are moving in opposite directions, creating a divergence in the central zone of the Strait from Punta Paloma to Punta Tarifa. It is worth noting, in the second flight image, that this divergence in the central zone of the Strait does not seem to induce any 'suction' of
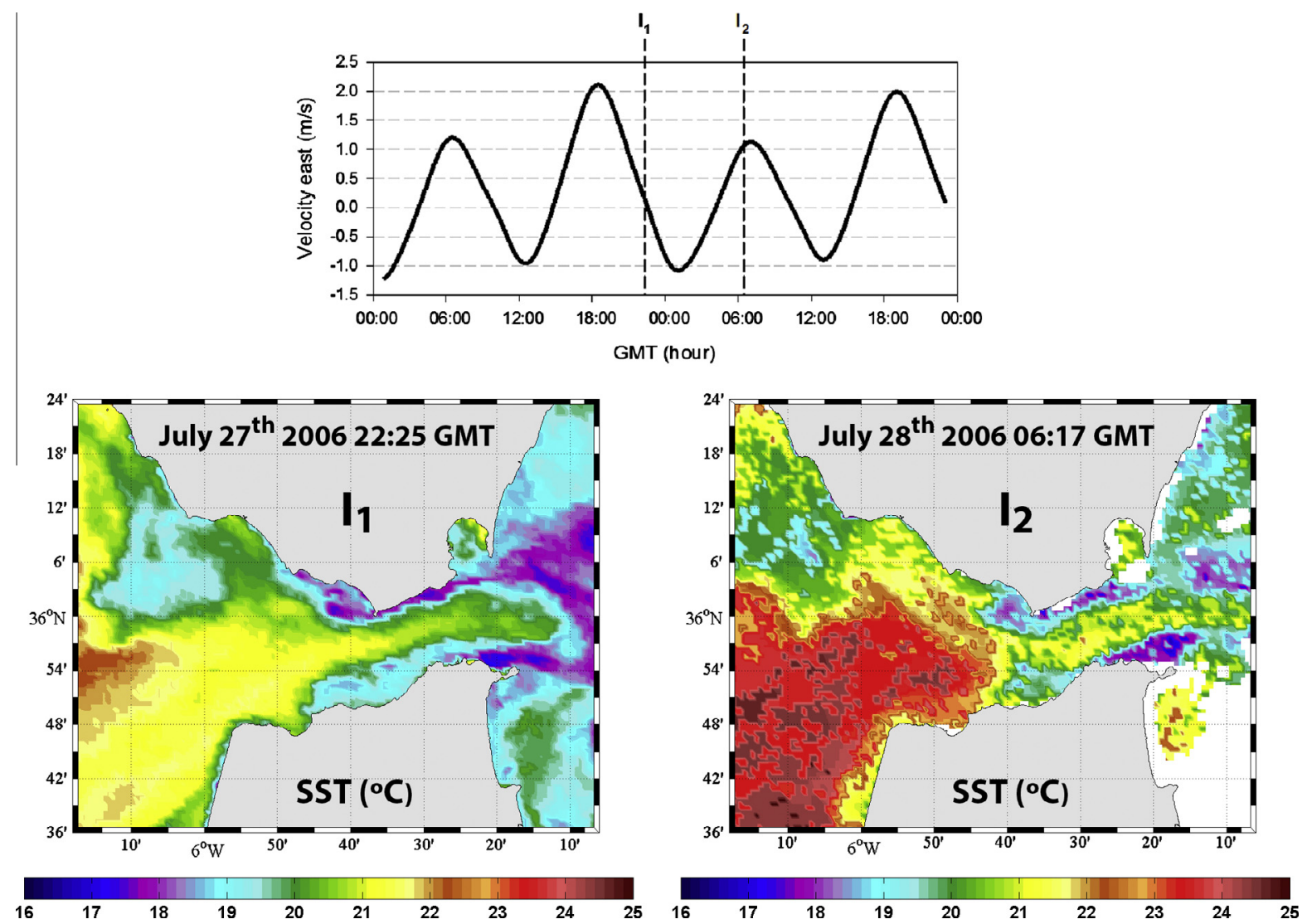

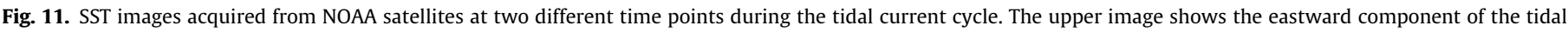
current velocity $(\mathrm{m} / \mathrm{s})$ at $45 \mathrm{~m}$ depth over the Camarinal Sill. 
coastal waters from the coastal margin regions. This absence of movement away from the coast suggests that upper layer divergence in this zone must be compensated by the rise of AMI waters toward the surface, which must surely contribute to the upper layer cooling via vertical mixing of the deeper waters of the AMI with the upper layer, induced by the strong currents in and near the Camarinal Sill region. The results presented here confirm the speculation of Macías et al. (2007), who proposed that 'suction' of coastal waters might take place between Punta Paloma and Punta Tarifa. On this new evidence, these transports seem to take place in the form of elongated patches of cold water that extend toward the central zone of the strait between Punta Paloma and Punta Camarinal.

These across-strait transports could be associated with the divergence zones created in the upper layer by the along-strait velocity gradient induced by the large amplitude internal waves over and to the west of the Camarinal Sill. For an illustration of this mechanism, we should look at Fig. 12, where a vertical section of current velocity across the internal wave fronts is shown. It can be seen that, in the zones where internal undulations bring the AMI to shallower depths (elevation wave), a very high westward current intensity is shown, while in the zones where AMI sinks to greater depths (depression wave), the westward current in the upper layer is reduced drastically, while in the lower layer the current is very intense. The reason for this velocity gradient in the upper layer across the internal wave fronts has already been explained in Bruno et al. (2002). Above the AMI elevations, wave-induced currents are moving westward coinciding with the tidal current, whereas above the AMI depressions, wave-induced currents are moving eastward in opposition to the tidal current. As a result, the westward current in the upper layer is intensified above the AMI elevations and reduced above the AMI depressions, giving rise to water mass convergence in the transitions (from east to west) between elevation and depression, and to water mass divergence between depression and elevation (see Fig. 12). We think that the zones with an increased southerly component of the current, along the transects $\mathrm{T} 3$ and T4, shown in Fig. 3, are caused by these upper layer divergences resulting from the interaction between the internal wave dynamics and the background tidal current in the central zone of the Strait.

As a consequence of these small-scale patterns of circulation, the suspended substances are moved from the coastal margins toward the central zones, and then are carried by the westward current toward the convergence zones created by the internal waves, where they tend to be retained and accumulate. Evidence of these accumulations has been reported by Macías et al. (2010) who analysed the zooplankton distribution along the internal wave fronts generated at the Camarinal Sill. Later, in the eastward phase of the tidal current over the Sill, these nuclei of concentrated substances (nutrients, chlorophyll, plankton) are transported toward the Alboran Sea, where they must contribute, to a certain extent, to the primary productivity there. In fact this could explain the
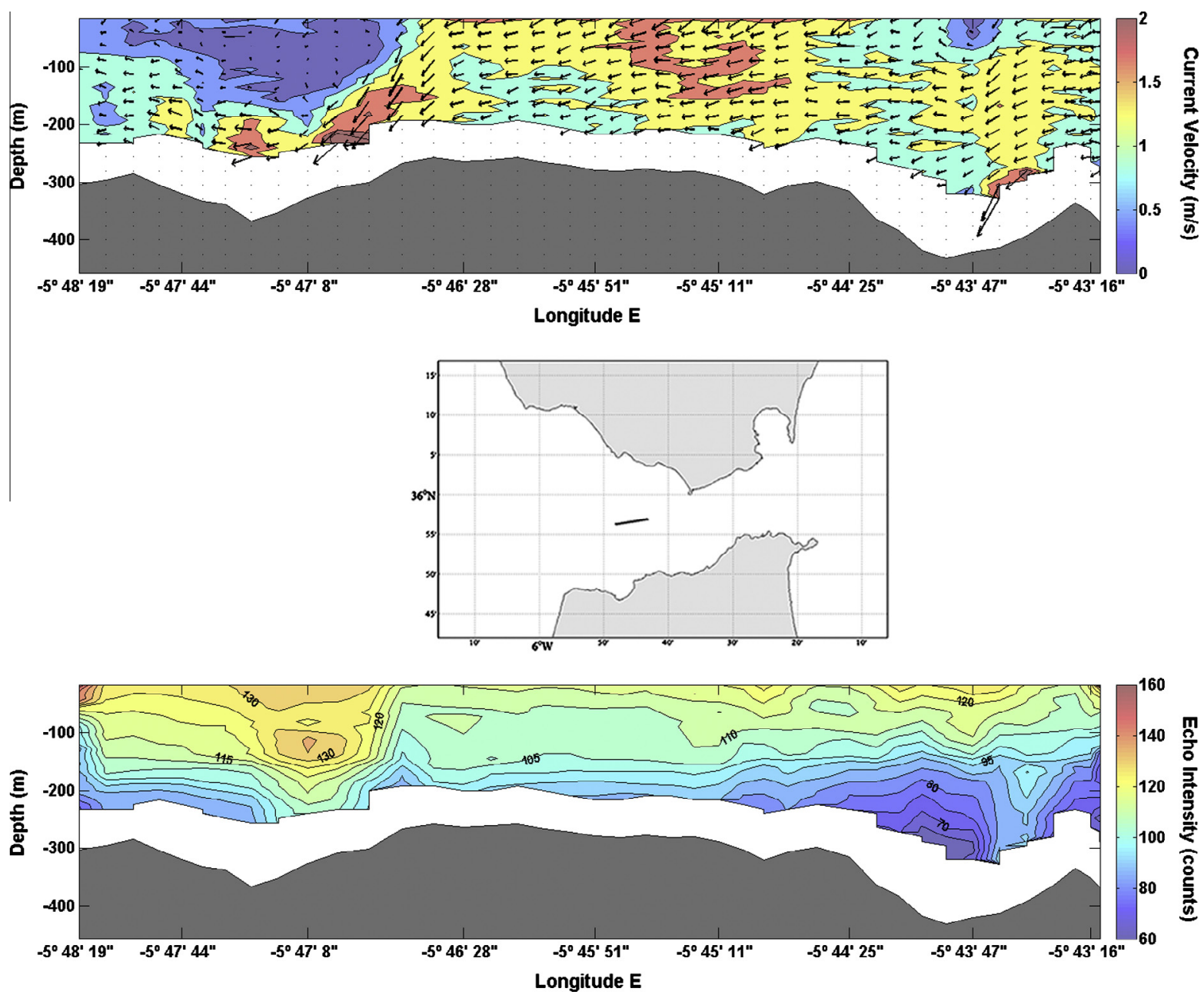

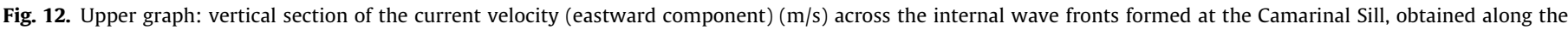
transect T3 (see Fig. 1). Lower graph: vertical section of echo intensity measured by the VM-ADCP. 


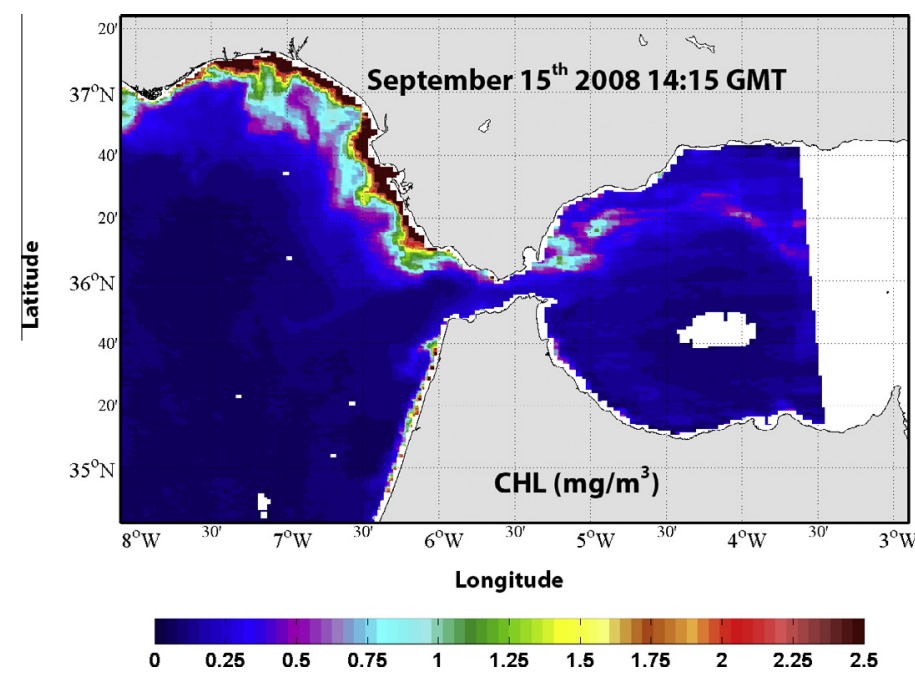

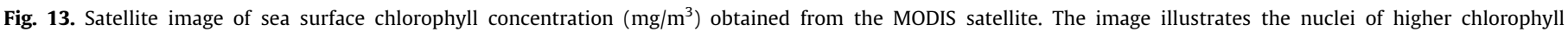
concentration entering the Alboran Sea from the Strait of Gibraltar.
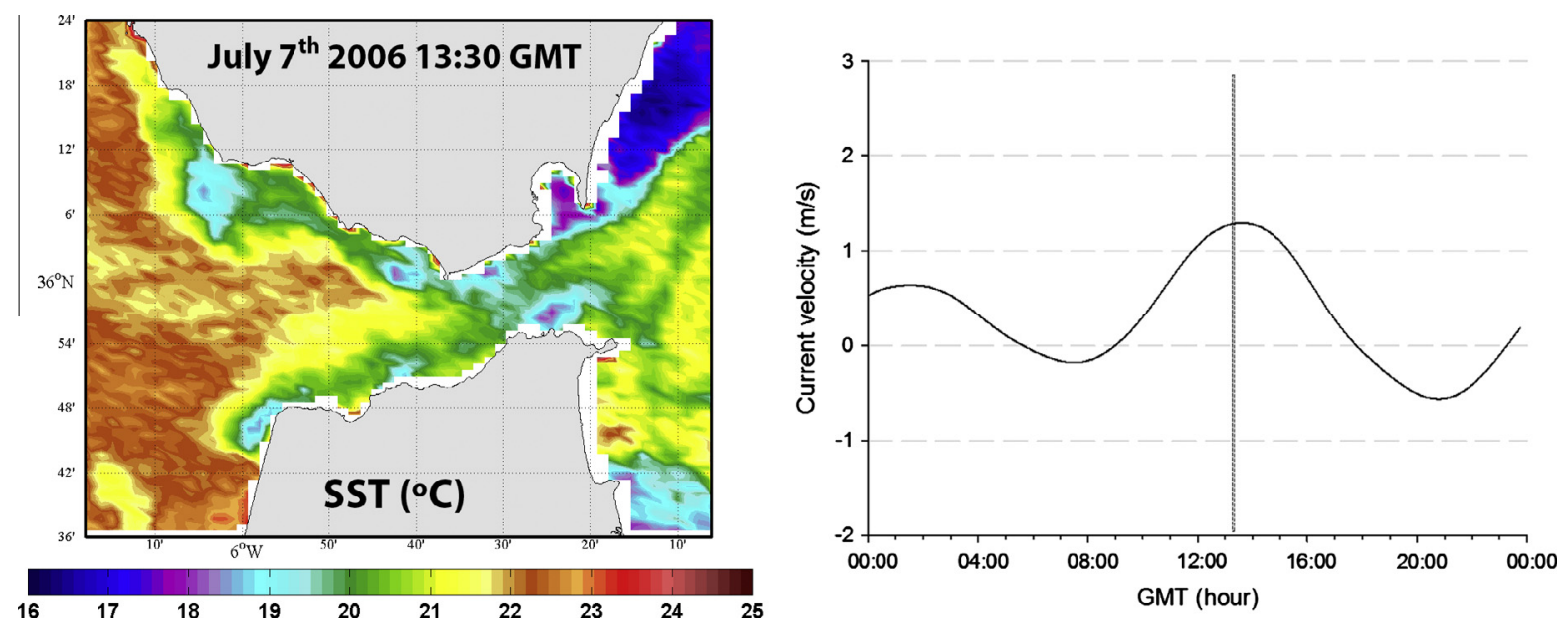

Fig. 14. SST image obtained from the MODIS satellite during the eastward phase of the tidal current, showing several pools of colder water along the coastal margin.

arrival at the eastern side of the Strait of the pulses of chlorophyll concentration reported by Macías et al. (2006). The instantaneous image of surface chlorophyll concentration presented in Fig. 13 shows an example of these nuclei of chlorophyll travelling immersed in the Western Alboran Gyre.

\subsection{Small-scale circulation patterns on the coastal margin}

Observing the instantaneous satellite images of SST shown in Fig. 14, eddy-like structures can be seen at the coastal margin, appearing as pools of colder water. At a higher spatial resolution, SST images acquired by airborne sensors, like that of Fig. 2, offer a good picture of a pool of colder water inside a cyclonic eddy of about 5 km width, located between Punta Paloma and Punta Tarifa.

Our hydrodynamic simulations reproduce the existence of a cyclonic eddy between Punta Paloma and Punta Tarifa (Fig. 8), which shows a clear tidal variability: it is more developed in the eastward phase of the tidal current. The existence of these eddies would explain the high chlorophyll concentration in these zones, in spite of the intense tidal dynamic prevailing in the central zone of the Strait. The eddies would act as traps in which water masses are partially retained on the coastal margin, for longer times of residence, escaping from the fast eastward advection imposed on the central zone of the Strait by the upper layer flow towards the Mediterranean. From the results of the Lagrangian experiment illustrated in Fig. 10, it can be deduced that a discrete water mass situated at the coastal margin, just to the west of Punta Camarinal, could stay for more than 12 days on the coastal margin before being definitively carried out through the Strait into the Mediterranean.

The coupling between the upwelling processes previously discussed and the cyclonic eddies forming at the coastal margin seems to be the mechanism that explains the higher chlorophyll concentration frequently found in those zones, because it makes possible a more or less continuous nutrient supply that, in turn, makes possible the phytoplankton growth in these areas. The phytoplankton 'suctioned' from the coast toward the central zone of the Strait is immersed in nutrient-rich waters and this fact may favour the growth of the phytoplankton while it is being transported to the Alboran Sea. It should be noted that the mere transport of phytoplankton through the Strait without undergoing these processes of nutrients supply and concentration would not produce the same growth possibilities; consequently the transport would be of less impact in defining the distribution of phytoplankton in the Alboran Sea. This last point highlights the importance of the sub-mesoscale processes acting in the region between Punta 

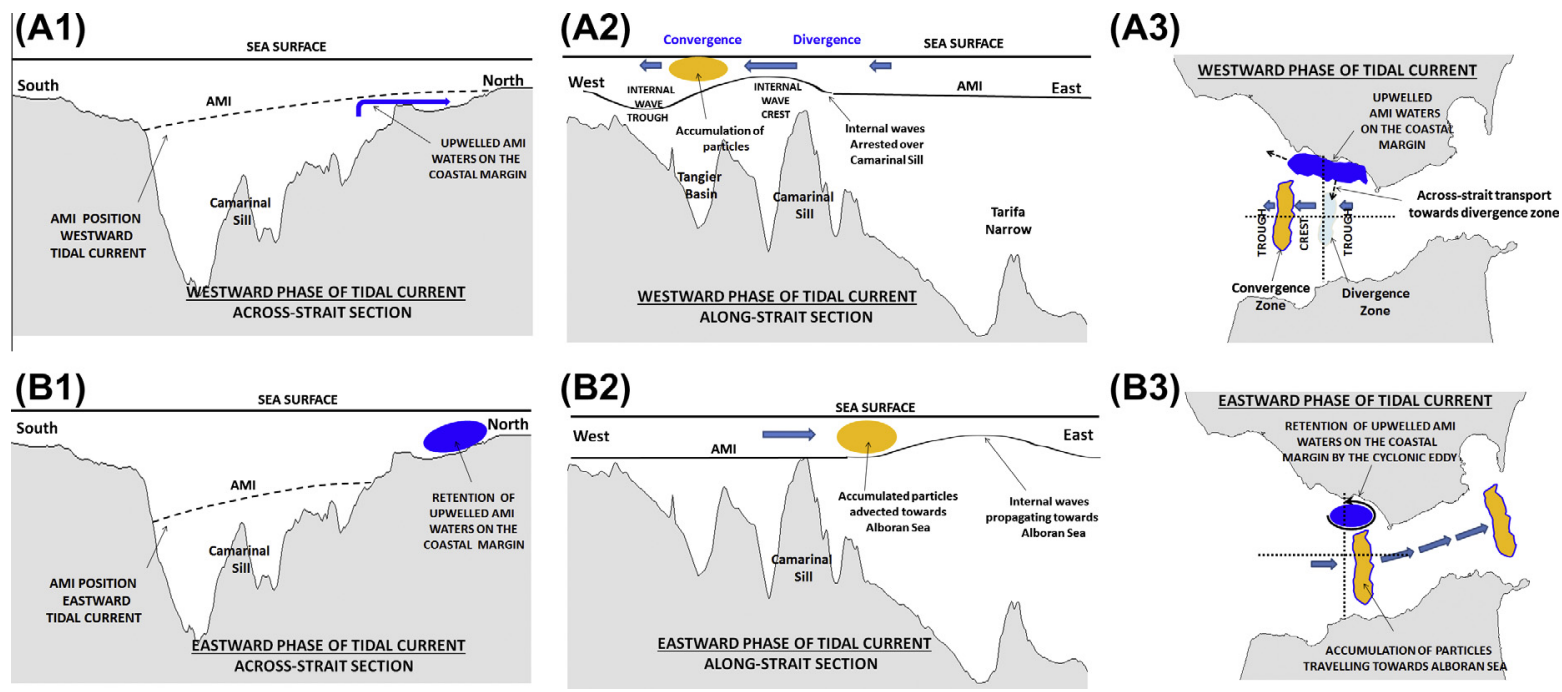

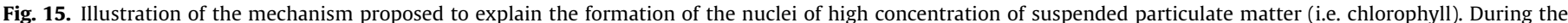

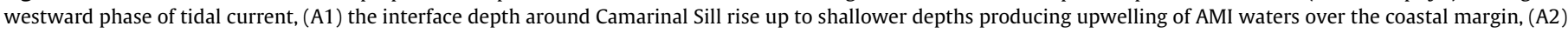

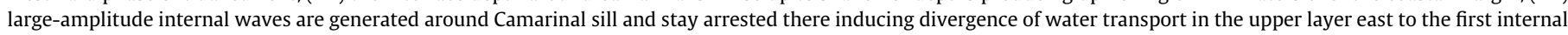

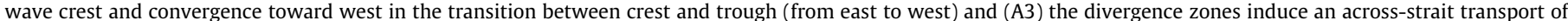

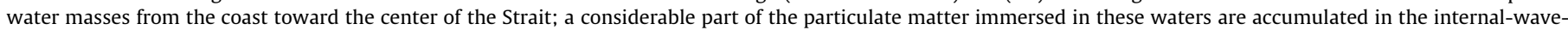

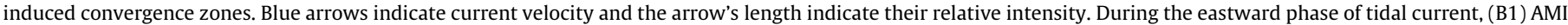

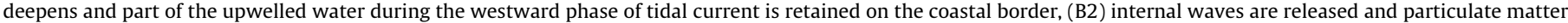

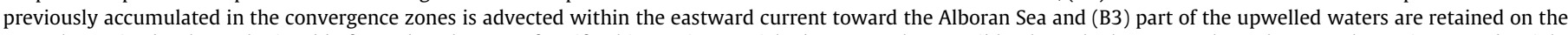

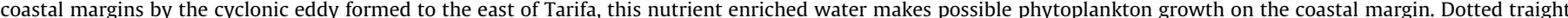

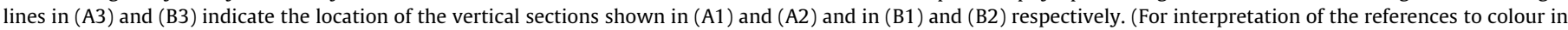
this figure legend, the reader is referred to the web version of this article.)

Camarinal and Punta Paloma for understanding the phytoplankton distribution in the Western Alboran Sea.

\section{Concluding remarks}

On the basis of the results presented two main factors are identified that should be taken into account for understanding the tidally-induced sub-mesoscale transport processes in the Strait of Gibraltar in the region of the Camarinal Sill:

(I) The kinematics of the AMI linked to the internal tide and the associated large-amplitude internal waves around Camarinal Sill, which induces:

(a) Vertical mixing processes in both the central zone and at the coastal margin of the Strait, providing nutrient-rich water to the upper layer and coastal waters.

(b) Divergence and convergence processes induced in the central zone of the Strait by the internal wave generation. These processes provoke the 'suction' of coastal waters towards the central zone of the Strait and the accumulation of particulate matter in the convergence zones created across the internal wave fronts.

(II) The presence of smaller tidal currents and tide-induced eddies at the coastal margins. These phenomena explain why the upwelling nutrient-rich water has a longer time of residence at the coastal margin between Punta Camarinal and Punta Tarifa.

The coupling between those processes provides the conditions for enhanced phytoplankton growth at the coastal margin between Punta Camarinal and Punta Tarifa, where coastal waters are wellsupplied with nutrients. Therefore the phytoplankton 'suctioned' from this coastal area toward the central zone is accompanied by nutrient-enriched waters, which favours its growth while it is being transported to the Alboran Sea. Fig. 15 attempts to illustrate how the involved processes interact giving rise to the transport of phytoplankton patches from the costal margins of the Strait of Gibraltar into the Alboran Sea. The results obtained highlight the importance of the sub-mesoscale processes acting in the region between Punta Camarinal and Punta Paloma for understanding the behaviour of phytoplankton in the Western Alboran Sea.

\section{Acknowledgements}

The present work has been funded by the Research Project: CTM2008-06421/MAR. The authors thank the Instituto Nacional de Técnica Aereospacial (INTA) for the use of the aircraft Paternina (CASA 212-200) porting the AHS scanner, which made possible the acquisition of the high-resolution SST images of the Camarinal Sill region.

\section{References}

Alonso del Rosario, J.J., Bruno Mejías, M., Vázquez-Escobar, A., 2003. The influence of tidal hydrodynamic conditions on the generation of lee waves at the main sill of the Strait of Gibraltar. Deep-Sea Research I 50, 1005-1021.

Armi, L., Farmer, D., 1988. The flow of Mediterranean water through the Strait of Gibraltar. Progress in Oceanography 21, 41-82.

Bruno, M., Alonso, J.J., Cózar, A., Vidal, J., Ruiz-Cañavate, A., Echevarría, F., Ruiz, J., 2002. The boiling-water phenomena at Camarinal Sill, the Strait of Gibraltar. Deep-Sea Research II 49, 4097-4113.

Bryden, H.L., Candela, J., Kinder, T.H., 1994. Exchange through the Strait of Gibraltar Progress in Oceanography 33, 201-248.

Candela, J., Winant, C., Bryden, H., 1989. Meteorologically forced subinertial flows through the Strait of Gibraltar. Journal of Geophysical Research 94, 12667 12679.

Candela, J., Winant, C., Ruiz, A., 1990. Tides in the Strait of Gibraltar. Journal of Geophysical Research 95 (C5), 7313-7335.

Candela, J., 1991. The Gibraltar Strait and its role in the dynamics of the Mediterranean Sea. Dynamics of Atmospheres and Oceans 15, 267-298.

García-Lafuente, J., Delgado, J., Vargas, J.M., Vargas, M., Plaza, F., Sarhan, T., 2002 Low frequency variability of the exchanged flows through the Strait of Gibraltar during CANIGO. Deep-Sea Research II 49, 4051-4067.

Instituto Geográfico Nacional and SECEG, 1988. Mapa Físico. Madrid, Spain.

Izquierdo, A., Tejedor, L., Sein, D.V., Backhaus, J.O., Brandt, P., Rubino, A., Kagan, B.A. 2001. Control variability and internal bore evolution in the Strait of Gibraltar: a 2-D two-layer model study. Estuarine, Coastal and Shelf Science 53, 637-651. 
La Violette, P.E., Arnone, R.A., 1988. A tide-generated internal waveform in the western approaches to the Strait of Gibraltar. Journal of Geophysical Research 93, 15653-15667.

Le Provost, C., Lyard, F., Molines, J.M., Genko, M.L., Rabillloud, F., 1998. A hydrodynamic ocean tide model improved by assimilating a satellite altimeter-derived data set. Journal of Geophysical Research 103, 5513-5529.

Macías, D., García, C.M., Echevarría, F., Vázquez-Escobar, A., Bruno, M., 2006. Tidal induced variability of mixing processes on Camarinal Sill (Strait of Gibraltar): a pulsating event. Journal of Marine Systems 60, 177-192.

Macías, D., Martin, A.P., García Lafuente, J., García, C.M., Yool, A., Bruno, M., Vázquez, A., Izquierdo, A., Sein, D., Echevarría, F., 2007. Mixing and biogeochemical effects induced by tides on the Atlantic-Mediterranean flow in the Strait of Gibraltar. An analysis through a physical-biological coupled model. Progress in Oceanography 74, 252-272.

Macías, D., Lubian, L.M., Echevarría, F., Huertas, E., García, C.M., 2008. Chlorophyl maxima and water mass interfaces: tidally induced dynamics in the Strait of Gibraltar. Deep-Sea Research I 55, 832-846.

Macías, D., Somavilla, R., González-Gordillo, I., Echevarría, F., 2010. Physical control on zooplankton distribution pattern at the Strait of Gibraltar during an episode of internal wave generation. Marine Ecology Progress Series 408, 79-95.
Richez, C., 1994. Airborne synthetic-aperture radar tracking of internal waves in the Strait of Gibraltar. Progress in Oceanography 33, 93-101.

Sein, D.V., Backhaus, J.O., Brandt, P., Izquierdo, A., Kagan, B.A., Rubino, A., Tejedor, L., 1998. Flow exchange and tidally induced dynamics in the Strait of Gibraltar derived from a two-layer, boundary-fitted coordinate model. In: Oceanic Fronts and Related Phenomena (Konstantin Fedorov Memorial Symposium). IOC Workshop Report Series, 159, UNESCO'98.

Vázquez, A., Stashchuk, N., Vlasenko, V., Bruno, M., Izquierdo, A., Gallacher, P.C., 2006. Evidence of multimodal structure of the baroclinic tide in the Strait of Gibraltar. Geophysical Research Letters 33, L17605.

Vázquez, A., Bruno, M., Izquierdo, A., Macías, D., 2008. The effect of meteorologically forced subinertial flows on internal waves generation at the main sill of the Strait of Gibraltar. Deep-Sea Research I 57, 1277-1283.

Vázquez, A., Flecha, S., Bruno, M., Macías, D., Navarro, G., 2009. Internal waves and short-scale distribution patterns of chlorophyll in the Strait of Gibraltar and Alborán Sea. Geophysical Research Letters 36, L23601.

Wesson, J.C., Gregg, M.C., 1994. Mixing at Camarinal Sill in the Strait of Gibraltar. Journal of Geophysical Research 99, 9847-9878. 